Hodgson-Jones, I, S. (1951), Brit, med. J 1, 795.

Horne, R. W., and Nagington, J. (1959). J. mol. Biol., 1, 333.

Lloyd, G. M., MacDonald, A., and Glover, R. E. (195i). Lancet, 1, 720 .

Lyell, A., and Miles, J. A. R. (1950). Brit. med. J., 2, 1119.

MacDonald. A. (1951). J. Path. Bact., 63, 758 .

Mair, H. J., and Tobin, J. O'H. (1960). Monthly Bull. Minist. Hlth Lab. Serv., 19. 49.

National Veterinary Medical Association of Great Britain and Ireland (1944). Report on Diseases of Farm Livestock, Section II. Diseases of Sheep, p. 39. N.V.M.A. Publications, No. 6 .

Paul, J. (1959). Cell and Tissue Culture, p. 68. Livingstone, Edinburgh.

Peterkin, G. A. G. (1937). Brit. J. Derm., 49, 492.

Plowright, W., Witcomb, M. A., and Ferris, R. D. (1959). Arch. ges. Virusforsch., 9, 214.

Stern, H., Elek, S. D., Millar, D. M., and Anderson, H. F. (1959). Lancet, 2, 871.

\section{PNEUMOCYSTIS PNEUMONIA}

REPORT OF THREE CASES IN ADULTS AND ONE IN A CHILD WITH A DISCUSSION OF THE RADIOLOGICAL APPEARANCES AND PREDISPOSING FACTORS

BY

\section{W. F. WHITE, M.B., B.S. House-surgeon}

H. M. SAXTON, M.B., F.F.R., M.R.C.P. Senior Registrar

AND

I. M. P. DAWSON, M.A., M.D., M.R.C.P. Reader in Pathology

Departments of Radiotherapy, Radiology, and Pathology, Westminster Hospital and Medical School, London

\section{[With Special Plate]}

In recent years, as the treatment of certain chronic diseases has become more effective, a number of agents previously considered as innocuous have been found to behave as pathogens. They flourish especially in tissues freed from competing organisms or deprived of their normal power of resistance by the actions, often combined, of radiotherapy, cytotoxic drugs, and longterm administration of antibiotics and corticosteroids. The marked increase in the incidence of fungal infections such as moniliasis and aspergillosis is an example of the development of this kind of "new" disease. A less common disease which may arise under similar conditions is Pneumocystis carinii pneumonia. We here report three adult cases and one case in a child of 2 years. Though it is not always certain to what extent the organism has behaved as a pathogen, there is little doubt that its multiplication in the lungs in these cases is associated with debilitating disease and corticosteroid therapy.

\section{Pathological Methods}

Five or more blocks from the lungs representing at least one block from each lobe were examined in every case. All sections were stained with haematoxylin and eosin, periodic-acid-Schiff (P.A.S.) stain, and Gömöri's methenamine silver method; Humperstone's modification of Le Tan's method (Symmers, 1960) was also used, but was less successful than Gömöri's technique in our hands. Gram stains and stains for fibrin were used as required. In Case 1, where pneumocystic infection was suspected before death, the right lung was fixed after distension (Gough and Wentworth, 1960) and, in addition to routine sectioning, a giant section was prepared for us by Professor Gough. In the other three cases the lungs were not artificially distended.

\section{Case Reports \\ Case 1}

A man aged 57 was diagnosed as having lymphosarcoma in 1954 following biopsy of a lymph node from the right supraclavicular fossa. A chest radiograph showed pronounced enlargement of hilar lymph nodes. Both sides of the neck and both axillae were irradiated, and he also received $43 \mathrm{mg}$ of nitrogen mustard in 14 days. Later in 1954 the chest and both groins were irradiated, after which the swelling of the hilar nodes regressed and he remained well until 1956, when he was found to have an enlarged spleen and enlarged lymph nodes in the neck, axillae, and groins. He received deep $x$-ray therapy to the abdomen, and in February, 1957, treatment with prednisone, $20 \mathrm{mg}$. daily, was started. He remained fairly well until November, 1959, when he became orthopnoeic and developed a severe cough. In January, 1960, his chest symptoms worsened and he became febrile. He was given tetracycline. later changed to erythromycin and novobiocin, with temporary clinical improvement. Lung biopsy was then performed and a provisional diagnosis of pulmonary alveolar proteinosis made. Following this he had a persistent left pneumothorax, which developed increasing tension necessitating decompression 17 days after biopsy; this resulted in some surgical emphysema. After temporary improvement his condition again worsened, and he died in February, 1960. He had been on corticosteroid treatment for three years.

Radiological Findings.-A chest radiograph taken on February 13,1959, before his final illness revealed only slight enlargement of the right hilum. On December 30, 1959 , a radiograph showed a bilateral " batswing " type of shadow more marked in the upper lobes and with some drawing up of the lesser fissure (Special Plate, Fig. 1). This shadowing had an over-all homogeneity, particularly on the "softer" films, but small translucencies. both rounded and tubular, could be seen within it. Many of these were obviously small air-filled bronchi; others presumably represented emphysematous air spaces. A penetrated film showed this more clearly. Though the consolidation was mainly central, producing a "hilar flare" appearance, there was no clear-cut margin and peripherally the lungs had a "ground-glass" appearance extending to the chest wall in the upper lobes. No pleural reaction was present. The heart size was normal. By January 15, 1960. the consolidation was denser and more extensive, and penetrated films showed definite "cyst" formation in a number of areas, the largest cyst measuring about $1.5 \mathrm{~cm}$. in diameter. A film taken after lung biopsy on January 22 showed extension of cyst formation in both upper lobes. There was a small left pneumothorax with a little basal fluid. The pneumothorax gradually increased until by February 8 there was a definite tension pneumothorax in the left upper zone with adherence of the lower lobe to the chest wall (Special Plate, Fig. 2). Further cystic change had occurred and a very large cyst was present in the collapsed left upper lobe. At this stage the pneumothorax was decompressed and the lung re-expanded.

The final film taken on February 14 showed multiple upper-lobe cysts, some with fluid levels (Special Plate, Fig. 3). There was fluid at the left base and widespread surgical emphysema following the decompression.

Necropsy Findings.-The trachea and main bronchi contained blood-stained mucus. In the right lung (examined after distension and fixation) were a number of irregular cavities radiating out from the hilum, and having a multilocular appearance attributed in part to the breaking-down of intervening lung tissue, as shown in the accompanying illustration. The walls of these cavities were predominantly 
smooth and fibrotic, but in places were ragged. The cavities themselves contained yellowish, turbid fluid, which was not purulent. Distal to the cavities the lung appeared consolidated. Bronchi could not be traced into the cavities and there was no evidence of bronchiectasis. A similar appearance was present in the left upper lobe, but here, though the lung immediately surrounding the cavities was consolidated, the peripheral lung was congested but still aerated. The left lower lobe was relatively normal. A fibrinous exudate was present over each lung, but there was no fluid in either pleural cavity.

Microscopically, there was diffuse pulmonary fibrosis with breakdown of many alveolar septa leading to cavity formation, which was more widespread than the naked-eye appearance suggested. Many remaining alveoli were dilated and emphysematous. The cavities were filled with eosinophilic material, some of which stained as fibrin, and many

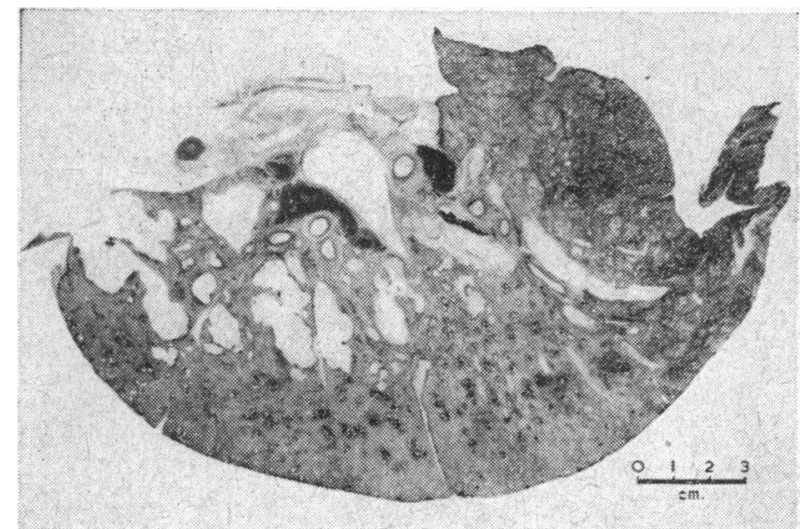

Giant section of lung from Case 1 showing distribution of cystic spaces around hilum.

contained finely vacuolated "honeycomb" material which stained positively with P.A.S. and Gömöri's methenamine silver and consisted of aggregates of Pneumocystis carinii (Special Plate, Fig. 4). In the areas of "consolidation" alveolar breakdown and emphysema were much less conspicuous, but large aggregates of Pneumocystis organisms were present (Special Plate, Fig. 5); in a few places there was superimposed purulent inflammation producing localized zones of bronchopneumonia. There was no evidence of residual lymphosarcoma.

\section{Case 2}

In a man aged 35 Hodgkin's disease was diagnosed in 1947 after biopsy of a lymph node in the left supraclavicular region. Between 1948 and 1957 he received radiotherapy to both supraclavicular fossae, the chest, and the abdomen. A second biopsy in 1957 disclosed active Hodgkin's disease, and he then received $36 \mathrm{mg}$. of nitrogen mustard over 16 days. In February, 1960, he had a further course of deep $x$-ray therapy to the right groin and right axilla, and in March was started on prednisone, $20 \mathrm{mg}$. daily. In July, 1960, he was admitted with pyrexia and rales at both bases and was treated with tetracycline, to which he responded. In September he was readmitted with productive cough, pyrexia, and anaemia (haemoglobin $6.6 \mathrm{~g}$. per $100 \mathrm{ml}$.) and was treated with erythromycin with temporary improvement. Signs of congestive heart failure with cyanosis, respiratory distress, and pulmonary oedema then developed, and after a further temporary response to treatment, he died. He had received corticosteroid therapy for six months.

Radiological Findings.-For the 15 months up to July, 1960 , there had been no change in his chest radiographs, which showed bilateral upper-lobe fibrosis with elevation of the hila. There were linear shadows thought also to be fibrotic in the lower zones. On September 9 patchy shadowing had developed in both lower zones, and by September 13 this had spread over both lung fields, being confluent in the left mid-zone and right upper lobe. There were small pleural effusions on both sides. The last film on September 15 showed further spread of the shadowing.

Necropsy Findings.-The trachea was healthy. Both lungs on section appeared beefy and oedematous; there were small, ill-defined indurated areas at the bases.

Microscopically there was conspicuous fibrous pleural thickening with a fibrinous pleural exudate. A severe but patchy fibrosis was present in both lungs, associated with intimal thickening and atheromatous change in some of the larger pulmonary arteries. Many alveoli adjacent to the fibrosed areas were dilated, and a number of them contained typical honeycomb colonies of pneumocystis. Some pulmonary oedema was present. There was no residual evidence of Hodgkin's disease.

\section{Case 3}

A man aged 30 was diagnosed as having Hodgkin's disease in 1954 following biopsy of a lymph node in the neck. He received irradiation to the side of the neck and mediastinum, and remained well until 1958, when his condition deteriorated and radiography of the chest showed infiltration of the left lung by Hodgkin's disease, left-sided pleural effusion, and a mediastinal mass indenting the left lung. He was given deep $x$-ray therapy to the left side of the chest and $40 \mathrm{mg}$. of nitrogen mustard over 16 days, after which he received prednisone, $30 \mathrm{mg}$. daily, and "leukeran" (chlorambucil), $6 \mathrm{mg}$. daily. Later he had $700 \mathrm{mg}$. of mannomustıne and further $x$-ray treatment to the right groin, right axilla, and right supraclavicular fossa. At this time the daily dose of prednisone was increased to $45 \mathrm{mg}$. He was readmitted in April, 1960, with dyspnoea and cyanosis. His condition deteriorated and he died the same month, having had continuous corticosteroid therapy for 18 months.

Radiological Findings.-A radiograph on January 11, 1960 , showed evidence of residual " fibrotic" left upper-lobe and right lower-zone shadowing, unchanged over the preceding 15 months. On admission on April 6, 1960, there was patchy bilateral lower-lobe shadowing, which by the 9th had increased and become confluent on the right side. No pleural reaction was present.

Necropsy Findings. - The trachea was healthy. Nearly the whole of the right lung and the lower lobe of the left lung were solid and contained a number of firmer pale areas, not sharply circumscribed. Around the left hilum, but separate from the pale areas and clearly distinct from them, was a thicker collar of fibrous tissue attributed to irradiated Hodgkin's disease.

Microscopically, there was thickening and fibrosis of alveolar septa with little tissue destruction-changes attributable to irradiation pneumonitis. Some alveoli were dilated and emphysematous, and in a few of these there was the typical P.A.S.-positive, silver-impregnated honeycomb material of Pneumocystis carinii. Some pulmonary oedema was also present. There was no microscopical evidence of Hodgkin's disease.

\section{Case 4}

This patient was a boy aged 2 years 5 months whose primary illness was diagnosed clinically as Letterer-Siwe's disease. At the age of 8 months he presented with the first of a series of febrile episodes characterized by hepatosplenomegaly and transient $x$-ray lung shadows, both of which disappeared when the fever subsided; on one occasion tests showed disturbed liver function. In later episodes he developed thrombocytopenia and severe anaemia (platelet count 23.000 per c.mm., haemoglobin 8.4 per $100 \mathrm{ml}$. ), at first intermittent, later permanent. At his last admission in November, 1959, he had crepitations, bronchial breathing, and marked hepato-splenomegaly with intermittent pyrexia, but no other physical signs; blood cultures, agglutination reaction, and other relevant investigations were at all times negative. He developed ecchymoses and purpura and terminally a hypogammaglobulinaemia with 
a very low serum $\beta$-globulin level; he died in February, 1960. From the age of 8 months until death he had received prednisone up to $40 \mathrm{mg}$. daily, at first intermittently to control the febrile episodes, but continuously for the last three months of life; he had also had intermittent treatment with tetracycline and erythromycin.

Radiological Findings.-Films during the final illness showed faint consolidation in both lungs, more obvious in the lower zones. The bronchi were visible as translucencies in the denser areas. No cysts were seen, nor was any pleural reaction noted.

Necropsy Findings.-The trachea and main bronchi contained thin purulent material. The cut surface of both lungs showed a curious mottled appearance consisting of small yellowish-white zones separated by apparently consolidated lung tissue. Some bronchi appeared dilated. There were a few small subpleural abscesses containing pus. Hilar lymph nodes were not enlarged.

Microscopically, many bronchi were dilated and contained pus. Two lesions appeared to be present in the lungs, the basic lesion being a patchy but fairly widespread pulmonary fibrosis. Many individual alveoli between fibrotic areas were dilated, but there was little destruction of alveolar walls. Many dilated alveoli contained fibrinous exudate and masses of vacuolated "honeycomb" material staining positively with P.A.S. and Gömöri's method. Superimposed on these lesions was a recent terminal bronchopneumonia with purulent alveolar exudation and abscess formation. There was no evidence of any malignant disease of lymphoid tissue or of Letterer-Siwe's disease. In both adrenals there was complete lipid depletion, and appearances were consistent with prolonged cortisone administration.

In none of the four cases was there any evidence of cytomegalic inclusions.

\section{Discussion}

Pneumocystis pneumonia in babies is well reviewed by Gajdusek (1957), and in adults by Rubin and Zak
(1960). Its pathology has been adequately described by Baar (1955), Hamperl (1956, 1957), Ahvenainen (1957), Symmers (1960), and others.

Many theories have been held as to the nature of the infecting organism. The Hungarian school, including Vaněk, Jírovec, and Lukeš (1953), first placed it among the Haplosporidia, itself an indeterminate group. Csillag and Brandstein (1954) were able to culture it and to produce a similar disease to the human variety by inoculation into the lungs of rabbits and mice; they considered it a member of the genus Saccharomyces. Simon (1953) regarded it as a form of Candida and claimed to have reproduced a similar disease in guineapigs. Giese (1953), however, placed it among the Blastomyces. No final conclusion has been reached. The subject is well reviewed by Gajdusek.

Pneumocystis pneumonia is not uncommon in Europe in debilitated or premature children aged 6 weeks to 6 months, in whom it is frequently described as interstitial plasma-cell pneumonia ; small epidemic outbreaks occur in hospitals, and plasma-protein levels, where estimated, have usually been normal (Ahvenainen) Cases among infants in Britain are rare; to the best of our knowledge seven have been reported up to the end of 1959 (Baar, 1955; Hutchison, $1955 \mathrm{a}$ and $\mathrm{b}$; Bird and Thomson, 1957; McKay and Richardson, 1959 ; Russell, 1959), all sporadic, of which five had hypogammaglobulinaemia or agammaglobulinaemia. Wilson et al. (1960) found only eight cases in the United States; the serum gammaglobulin levels were unrecorded in six and low in two. Twenty-six cases in infants have been reported from Canada (Berdnikoff, 1959; Junger and Wyllie, 1959; Hendry and Myers, 1959), but gammaglobulin levels were not recorded.

Adult cases are rare in all countries. Rubin and Zak (1960) reported one case and reviewed 13 others, not

Table Showing Reported Adult Cases of Pneumocystis Pneumonia

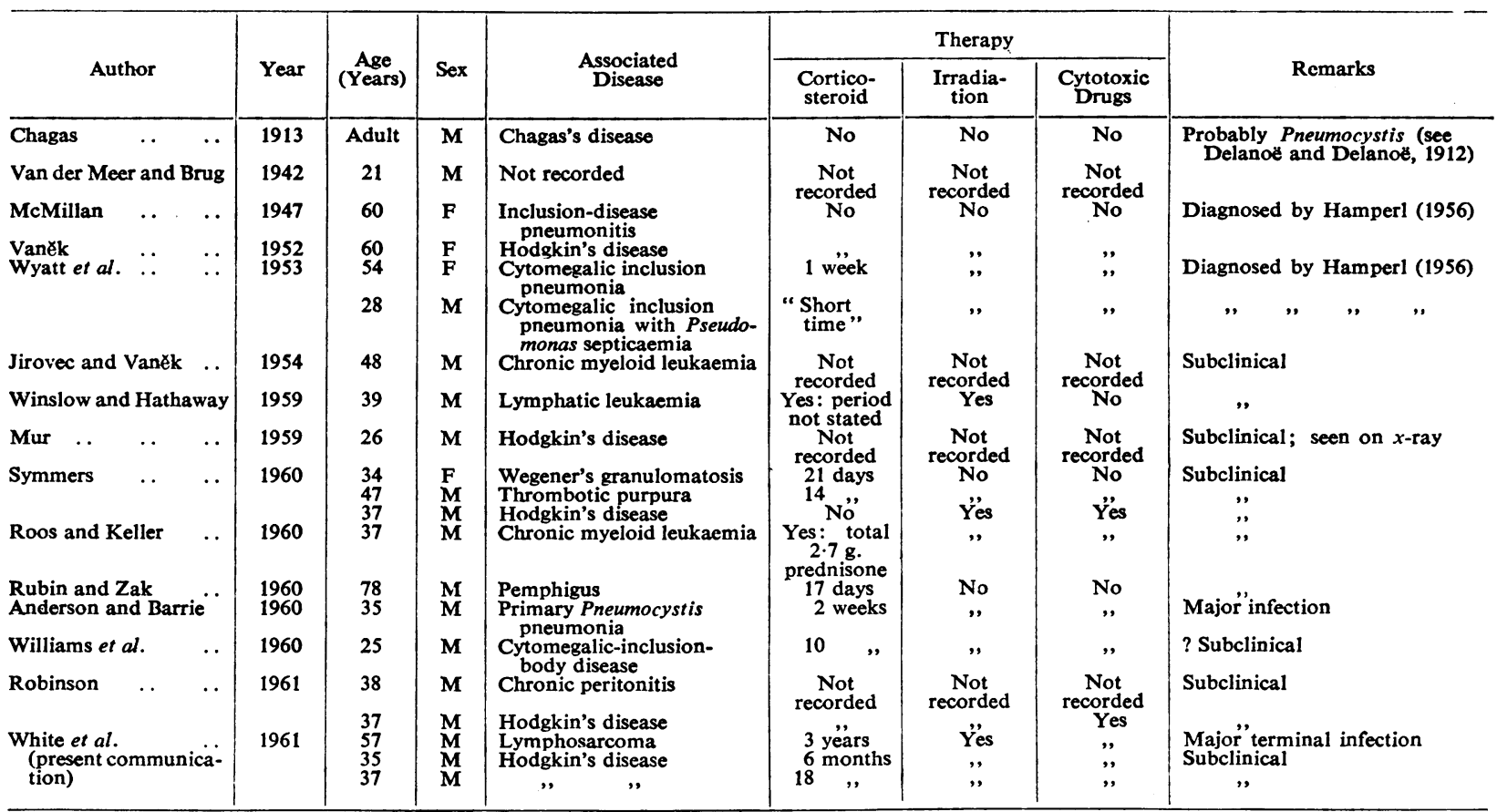

NoTE.-An attempt was made to summarize the antibiotics used, but since in many cases the period of time for which any antibiotic was administered was not given, and in some cases the antibiotic used was not recorded, no useful information resulted.

In cases where no record of treatment is given, therapy is marked as " not recorded" Where full or reasonably full details of treatment are given, and corticos teroids, irradiation, or cytotoxic drugs are not mentioned, they are recorded as not having been given. 
all of which were proved ; two more are mentioned by Robinson (1961) and one each by Anderson and Barrie (1960) and Williams et al. (1960). In the great majority of adult cases the plasma-protein levels are not recorded; in the last two cases mentioned they were normal or slightly raised. The fact that we have seen three adult cases in 18 months suggests that the condition is in fact not uncommon but often passes unrecognized.

\section{Predisposing Factors}

Our four cases have certain factors in common with each other and with those described by Rubin and Zak. All had cyanosis and respiratory distress without marked physical signs. In Cases 1 and 4 these were attributed directly to Pneumocystis infection, while in Cases 2 and 3 they were probably due to pulmonary oedema. The three adults certainly and the child probably suffered from malignant disease of the reticulo-endothelial system; this by itself is unlikely to be a predisposing factor, since involvement of the lungs in such conditions is not uncommon, while Pneumocystis infection is apparently rare. The treatment these cases received may, however, have predisposed to infection. All of our four cases, and six of the other cases recorded in the Table, had continuous long-term corticosteroid therapy for three months or more before death. There is experimental evidence that corticosteroids may encourage the growth of Pneumocystis. Pliess and Trode (1958) produced infection in rats by the administration of penicillin and cortisone, and Ricken (1958) obtained similar results with cortisone only, which presumably promoted the growth of Pneumocystis organisms already present in the lungs as saprophytes. Similarly Sheldon (1959a), in a series of experiments on rabbits, found not only that cortisone facilitated the growth of a suspension of Pneumocystis organisms introduced into the lungs but that a control group of rabbits given cortisone alone also developed Pneumocystis infection, presumably from saprophytes. Such latent infection is found in other animals (Carini and Maciel, 1915). Pneumocystis is said also to be a saprophyte in man (Weisse and Wedler, 1954), and subclinical infections resembling the latent infection in rabbits have been described by Sheldon (1959b) as occurring in children who had not received corticosteroids; it seems that long-term corticosteroid therapy might well promote the growth of the organism as Sheldon suggests. Now that such therapy is common it will be interesting to see whether more cases occur.

Other possible factors influencing the development of the disease are long-term antibiotic therapy, which may encourage the growth of Pneumocystis by inhibiting the growth of other organisms in the respiratory tract; administration of cytotoxic drugs; and radiotherapy to the lung. The last two factors may act by damaging the lung and so encouraging the growth of saprophytes. It is doubtful whether they have any direct effect on the growth of the organism; irradiation of rats did not enhance the lesions of Pneumocystis (Goetz and Rentsch, 1957).

\section{Gamma-globulin Levels}

In the majority of adult cases the gamma-globulin levels are either normal or unrecorded; hypogammaglobulinaemia is probably uncommon. Analysis of the disease in children suggests that there may be two types: one, more common in Europe, in which the cases may be epidemic, the age incidence is below 6 months, gamma-globulin levels are normal, and plasma cells occur in the interstitial tissue of the lung; the other, more common in Britain and America, in which the cases are sporadic, the age incidence is slightly older (often up to 12 months), hypogammaglobulinaemia is common, and plasma cells are not a feature. Ricken's work on rats suggested that animals with low resistance showed Pneumocystis in colonies in the lungs without reaction, while those with more resistance developed chronic interstitial inflammation. Hypogammaglobulinaemia is associated with lowered resistance to many forms of infection, and this may partly account for the lack of interstitial inflammation in non-European cases. Most adult cases are sporadic and serum globulin levels have not been adequately investigated; further investigations of globulin levels in suspected cases are needed. In children with respiratory disease whose gamma globulins are at a low level or absent the possibility of Pneumocystis infection should therefore be entertained.

\section{Histopathology}

The histological diagnosis of Pneumocystis infection is not difficult if the condition is suspected and specific stains are used. The question arises, however, as to how much the comparatively extensive pathological change seen in the lungs in adult cases is due directly to Pneumocystis infection and how much to the original disease with or without treatment by irradiation. In the majority of cases in infants-though our Case 4 is an exception-previous lung damage is unlikely, and the changes of interstitial pneumonia with masses of organisms in dilated alveoli found in the lungs may properly be attributed to the Pneumocystis infection. The accompanying emphysema may be caused by large masses of intra-alveolar parasites acting as ball-valves and obstructing expiration or may be a compensatory emphysema following interstitial inflammation with fibrosis. In our 3 adult cases, however, the pulmonary fibrosis is more than would be expected in an uncomplicated interstitial pneumonia, and we feel that the greater part of the change in these cases was due to antecedent disease or reaction to irradiation, though in Case 1 the cyst formation was probably directly due to the Pneumocystis infection.

\section{Radiological Aspects}

Full accounts of the radiological evolution of the disease in children have been given by Garsche (1951), Jacob (1954), and Bori and De Marco (1955). Garsche described three stages: that of oedema (better termed the exudative stage), that of collapse, and that of emphysema. This division is used for descriptive convenience and different stages may coexist.

In the first or exudative stage there is a ground-glass shadowing in both upper and middle zones maximal around the hila and obscuring the heart outline. It is usually relatively symmetrical and gradually extends outwards and downwards, though the lower zones laterally, and particularly the costophrenic regions, tend to be spared. This corresponds with the stage of proteinaceous exudation into the alveoli and multiplication of the parasite within them. The bronchi remain "dry" and may show as translucencies through the area of consolidation. 
With the onset of the second stage - that of collapsethe shadowing loses its homogeneity. Multiple areas of lobular collapse occur, giving a finely mottled appearance. Intervening small areas of emphysema may produce a honeycomb effect. Later the areas of collapse become confluent and ragged with an irregular distribution.

In the third stage - that of emphysema-the areas of emphysema grow larger, and are particularly marked in the lower zones and anteriorly with flattening of the diaphragm. There may be not only pulmonary emphysema, but interstitial, mediastinal, and subcutaneous emphysema. Pneumothorax may also occur, often with little collapse because of the rigidity of the affected lung. Pneumopericardium has been described.

At any stage enlargement of hilar lymph nodes or pleural involvement is unusual unless there is secondary infection.

Our Case 4 had radiological changes consistent with Stage 1 of the disease, but at necropsy some of the lung shadowing was found to be due to bronchopneumonia. Of the adult cases, only Case 1 showed a picture similar to that of the infantile disease, and in this respect appears unique among reported cases. When first seen the case was in early Stage II with ground-glass shadowing peripherally and an early honeycomb appearance centrally, best seen on more penetrated films. This later coarsened and spread peripherally with, ultimately, marked cyst formation. Though the pneumothorax was initially due to operation, its persistence was almost certainly associated with the cyst formation.

The other two adult cases showed a nondescript pattern of patchy consolidation becoming confluent in places. This was shown later to be due in part to pulmonary oedema, which was in fact the radiological diagnosis. Most adult cases will be of this kind, with scattered areas of infection occurring terminally and without characteristic features. The differential diagnosis will include bronchopneumonic consolidation, pulmonary oedema, pulmonary infarct, pulmonary eosinophilia, or even infiltration by reticulosis. Only a knowledge of the clinical background may lead to the suggestion of Pneumocystis pneumonia among other possibilities.

In Case 1 the possible diagnoses considered were pulmonary alveolar proteinosis, chronic pulmonary oedema, atypical Hodgkin's infiltration, and sarcoidosis. Of these, only pulmonary alveolar proteinosis seemed at all likely, and the lung biopsy appeared to bear out this diagnosis. The appearances described in alveolar proteinosis (Rosen et al., 1958) are similar, but the shadowing is usually more basal in distribution, and, although areas of emphysema may occur, cyst formation is not mentioned. Even were the similarity greater, the clinical background would still weigh the diagnosis in favour of Pneumocystis infection, since pulmonary alveolar proteinosis usually occurs in previously healthy subjects and, with some exceptions, has not followed corticosteroid therapy.

\section{Summary}

Pneumocystis pneumonia was found in three adults and one child aged $2 \frac{1}{2}$ years. The adults had histologically proved and the child clinical evidence of primary malignant disease of lymphoid tissue. All had received long-term corticosteroid and antibiotic therapy ; the adults had also had cytotoxic drugs and radiotherapy.

Review of these cases suggests that Pneumocystis pneumonia should be considered when cyanosis and breathlessness are out of proportion to physical signs, or when unexplained pulmonary consolidation is present in the later stages of reticulosis. A consideration of treatment received suggests that long-term corticosteroid therapy predisposed to the condition, and review of the experimental literature supported this view. There is some evidence that in children the disease may present in two forms, depending on the general resistance, and that poor resistance may sometimes be linked with low gamma-globulin levels.

We wish to thank Dr. I. M. Anderson and Dr. K. Newton for permission to publish clinical details of their patients; Dr. A. D. Morgan for the necropsy reports on Cases 2 and 3 ; Dr. P. Kerley and Dr. B. Strickland for advice on the radiological appearances; and Professor $\mathrm{J}$. Gough for help and encouragement and for the giant section of lung illustrated.

\section{REFERENCES}

Ahvenainen, E. K. (1957). Pediat. Clin. N. Amer., Feb., p. 203. Anderson, C. D., and Barrie, H. J. (1960). Amer. J. clin. Path., 34, 365 .

Baar, H. S. (1955). J. clin. Path.. 8, 19.

Berdnikoff, G. (1959). Canad. med. Ass. J., 80, 1.

Bird, T., and Thomson, J. (1957). Lancet, 1, 59.

Bori, V.' D., and De Marco, B. (1955). Lattante, 26, 250.

Chagas, C."(1913). Brasil-méd., 27, 225.

Carini, A., and Maciel, J. (1915), Zbl. Bakr., Abt. 1 (Orig.), 77, 46 ; cited by Sheldon (1959a).

Csillag, A., and Brandstein, L. (1954). Acta microbiol. Acad. Sci. hung., 2, 179.

Delanoë, P., and Delanoë, Mme (1912). C.R. Acad. Sci. (Paris), 155, 658 .

Gajdusek, D. C. (1957). Pediatrics, 19, 543.

Garsche, R. (1951). Fortschr. Röntgenstr., 75, 125.

Giese (1953). Zbl. allg. Path. path. Anat., 90, 54.

Goetz, O., and Rentsch, L. (1957). Kinderheilk, 79, 578

Gough, J., and Wentworth, J. E. (1960). In Recent Advances in Pathology, 7th ed., ed. C. V. Harrison, p. 80. Churchill, London.

Hamperl, H. (1956). Amer. J. Path., 32, 1.

- (1957). J. Path. Bact., 74, 353.

Hendry, J., and Myers, R. F. (1959). Canad. med. Ass. J., $81,83 i$.

Hutchison, J. H. (1955a). Lancet, 2, 844.

(1955b). Ibid., 2, 1196.

Jacob, G. (1954). Fortschr. Röntgenstr., 80, 697.

Jírovec, O., and Vaněk, J. (1954). Zbl. allg. Path. path. Anat., 92, 424.

Junger, P. W., and Wyllie, J. (1959). Canad. med. Ass. J.. 80, 35 .

McKay, E., and Richardson, J. (1959). Lancet, 2, 713.

McMillan, G. C. (1947). Amer. J. Path., 23, 995.

Mur, J. (1959). Zbl. allg. Path. path. Anat., 99. 386.

Pliess, G., and Trode, H. (1958). Frankfurt Z. Path., 69, 231.

Ricken, D. (1958). Virchows Arch. path. Anat., 331, 713.

Robinson, J. J. (1961). Arch. Path., 71, 156.

Roos, B. von, and Keller, H. (1960). Path. et Microbiol. (Basle), 23, 277.

Rosen, S. H., Castleman, B., and Liebow, A. A. (1958). New Engl. J. Med.. 258. 1123 ,

Rubin, E., and Zak, F. G. (1960). Ibid., 262, 1315.
Russell, J. G. B. (1959). Arch. Dis. Childh., 34, 338.

Sheldon, W. H. (1959a). J. exp. Med., 110, 147

- (1959b) Amer. J. Dis Child 97, 287

Simon, H. (1953). Naturwissenschaften, 40,625, cited by Gajdusek.

Symmers, W. St. C. (1960). J. clin. Path., 13, 1.

Van der Meer, G., and Brug, S. L. (1942). Ann. Soc. belge Méd. trop., 22, 301

Vaněk, J. (1952)). Čas. Lék. čes., 91, 1260.

Jírovec, O., and Lukeš, J.' (1953). Ann. paediat. (Basle),

180, 1.
Weisse, K., and Wedler, E. (1954). Klin. Wschr., 32, 270.

Williams, G., Stretton, T. B., and Leonard, J. C. (1960). Lancet, 2, 951., Stretton, T. B., and Leonard, J. C. (1960). Lancet,

Wilson, J. F., Crass, G., and Garza, B. L. (1960). Pediatrics, 25, 468 .

Winslow, D. J., and Hathaway, B. M. (1959). Amer. J. clin. Path., 31, 337.

Wyatt, J.'P., Simon, T., Trumbull, M. L., and Evans, M. (1953). Ibid., 23, 353. 
W. F. WHITE, H. M. SAXTON, AND I. M. P. DAWSON: PNEUMOCYSTIS PNEUMONIA

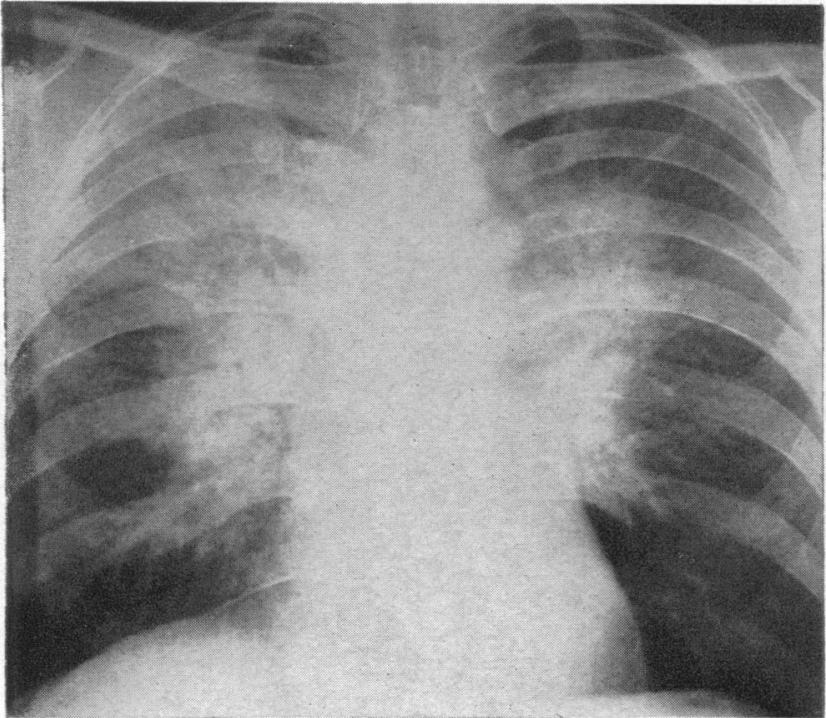

Fig. 1.-Case 1. Radiograph taken on admission on December 30, 1959, showing "batswing" shadowing.

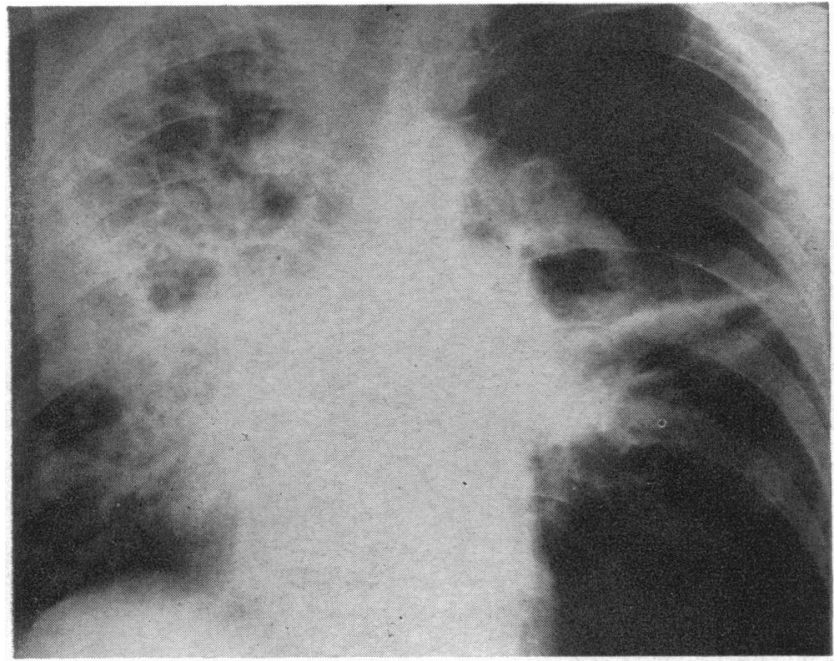

FIG. 2-Case 1. Radiograph taken on February 8, 1960, showing left pneumothorax, large cyst in collapsed left upper lobe, and widespread cystic change in right lung.

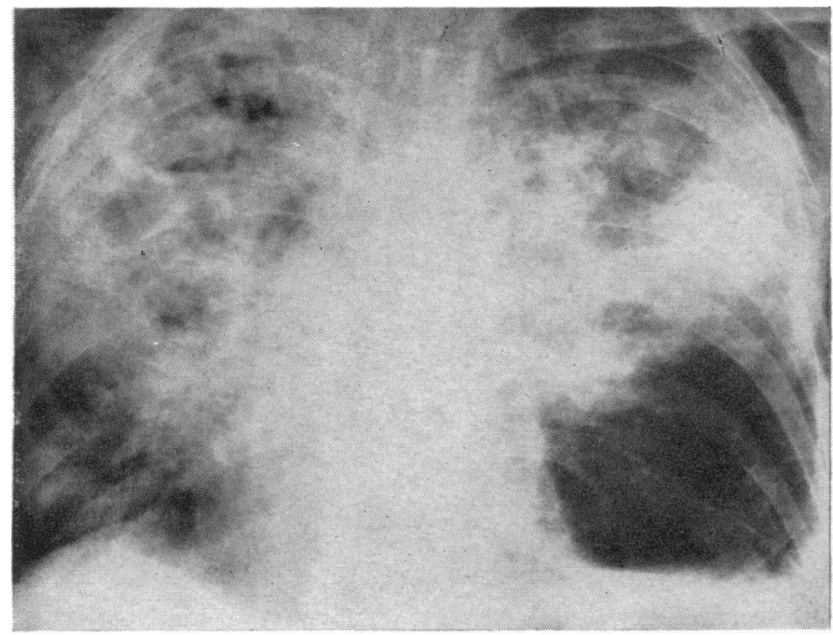

Fig. 3.-Case 1. Radiograph taken on February 14, 1960, showing re-expansion of left lung. There are fluid levels in a number of the larger cysts.

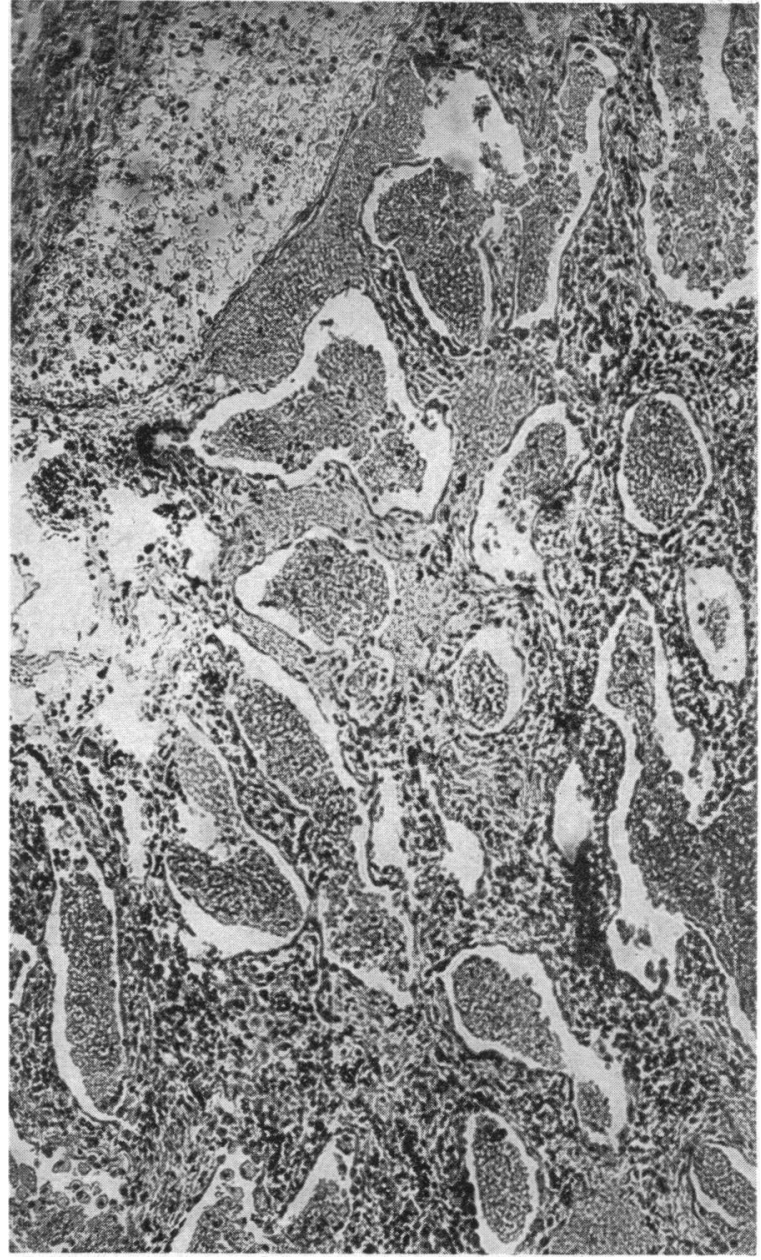

FIG. 4.-Case 1. Section of lung showing cavities and dilated alveoli containing masses of " honeycomb "Pneumocystis organisms. (Haematoxylin and eosin. $\times 75$.)

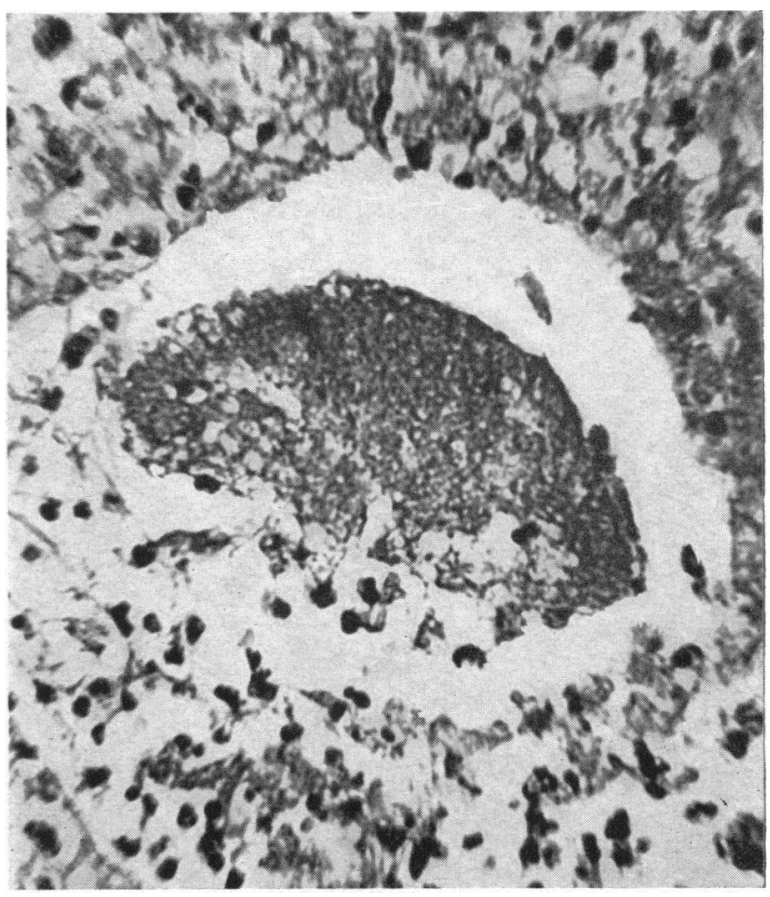

Fig. 5.-Case 1. Section to show Pneumocystis organisms. (Periodic-acid-Schiff. $\times 450$.) 